\title{
Kinetic Studies on Bulk Atom Transfer Radical Polymerization of Styrene
}

\author{
Samiul Islam Chowdhury ${ }^{1, ~ *, ~ L a m y a ~ Z a h i r ~}{ }^{2}$, Tariqul Hasan ${ }^{3}$ \\ ${ }^{1}$ Department of Chemistry, Bangladesh University of Textiles, Dhaka, Bangladesh \\ ${ }^{2}$ Department of Apparel Engineering, Bangladesh University of Textiles, Dhaka, Bangladesh \\ ${ }^{3}$ Department of Chemistry, University of Rajshahi, Rajshahi, Bangladesh
}

\section{Email address:}

sami_butex13@yahoo.com (S. I. Chowdhury)

${ }^{*}$ Corresponding author

\section{To cite this article:}

Samiul Islam Chowdhury, Lamya Zahir, Tariqul Hasan. Kinetic Studies on Bulk Atom Transfer Radical Polymerization of Styrene. American Journal of Polymer Science and Technology. Vol. 3, No. 6, 2017, pp. 103-107. doi: 10.11648/j.ajpst.20170306.12

Received: November 9, 2017; Accepted: December 1, 2017; Published: December 21, 2017

\begin{abstract}
The long chain vinyl end-functional polystyrene has been synthesized in bulk polymerization method using atom transfer radical polymerization (ATRP) with Undecenyl-2-Bromopropionate (UnBP) and $\mathrm{CuCl} /$ bypyridine catalytic system. The polymerizations demonstrate an increase in molecular weight and conversion in direct proportion to the polymerization time by consumed monomer which exhibited first-order kinetics. This study concludes the simple kinetics of polystyrene synthesized by ATRP using initiator and ligand-to-copper(I) halide was found to be 1:2:1, which tentatively indicates that the coordination sphere of the active copper(I) center contains two bipyridine ligands. The propagation rate has been investigated for long range of time for ensuring that the rate of radical combination or disproportionation is sufficiently less.
\end{abstract}

Keywords: Polystyrene, Initiator, ATRP, Bulk Polymerization, Kinetics

\section{Introduction}

In polymer chemistry, the development of Living Radical Polymerization (LRP) via ATRP technique constitutes one of the key developments in the field of synthetic polymer chemistry, allowing for the synthesis of a variety of polymers with molecular weight distributions and well defined architectures, with precise control over the compositions and structures [1-3]. In general, a combination of an alkyl halide $[\mathrm{R}-\mathrm{X}, \mathrm{X}=\mathrm{Cl}$ or $\mathrm{Br})]$ and a transition metal catalyst in lower oxidation state $\left(\mathrm{Cu}(\mathrm{I}) \mathrm{X} / 2,2^{\prime}\right.$-bipyridine $)$ is used to initiate the ATRP system [4-6]. The resulting polymers have degrees of polymerization predetermined by $\Delta[\mathrm{M}] /[\mathrm{I}]_{0}$ up to $M_{\mathrm{n}}-10^{5}$ and low polydispersities in range $1.05<M_{\mathrm{w}} / M_{\mathrm{n}}<1.5$ [7]. For example, styrene is polymerized by atom transfer radical additions using 1-phenylethyl chloride [8] or arenesulfonyl chloride [9] as an initiator and $\mathrm{CuCl} / 4,4^{\prime}$-diheptyl-2,2'bipyridine or 4,4'- $\operatorname{di}(5$-nonyl)-2,2'-bipyridine (dNbipy) complex as the catalyst to yield a well-defined polymer with a narrow molecular weight distribution $\left(M_{\mathrm{w}} / M_{\mathrm{n}}=1.05\right)$. The kinetics of syndiospecific slurry polymerization of styrene in heptane has been investigated with pentamethylcyclopentadienyl titanium trimethoxide $\left[\mathrm{Cp}^{*} \mathrm{Ti}(\mathrm{OMe})_{3}\right]$ catalyst with methylalmuninoxane [10]. Confinement effect of graphene nanoplatelets on the kinetics of styrene atom transfer radical polymerization was studied by a grafting from reaction [11]. The kinetic studies of atom transfer radical polymerizations of styrene and chloromethylstyrene has been studied with poly(3-hexyl thiophene) macroinitiator for synthesis of Poly(3-hexyl thiophene)- $b$-poly(styrene-co-chloromethylstyrene)

copolymers [12]. The structure of the alkyl halide initiator should be adjusted for each class of monomers to generate a rate of initiation at least equal to the rate of propagation [13]. Considering this point, most authors prefer to use activated alkyl initiating systems with a chemical surrounding as similar to the growing polymer chain end as possible. The rate constant of initiation for styrene is higher than the rate constants of propagation $[14,15]$. The kinetic study is investigated of bulk free radical polymerization of styrene initiated with the commercial bifunctional initiator 2,5dimethyl-2,5-bis(2-ethyl hexanoyl peroxy)hexane [16] and 
with $\alpha, \alpha$-dichlorotoluene (DCT) as initiator [17]. According to the kinetic study of styrene ATRP, the polymerization proceeds by monomer addition to free radicals which are reversibly generated by an atom transfer process from dormant polymer chains with halide end groups [18]. In these reactions, a small amount of $\mathrm{Cu}$ (II) species are considered to serve as a deactivator which moderates reaction rates and are responsible for maintaining low polydispersities [19, 20]. The $\mathrm{Cu}$ (II) species can be separately added to the system or can be formed spontaneously by the so-called persistent radical effect [21]. A rough estimate of the amount of $\mathrm{CuBr}_{2} / \mathrm{dNbipy}$ species formed from kinetic studies was $\sim 5 \%$, based on the $\mathrm{CuBr} / \mathrm{dNbipy}$ catalyst [4]. Kinetic modeling is used to better understand and optimize initiators for continuous activator regeneration atom-transfer radical polymerization (ICAR ATRP) [22-24]. Here, the report presents a kinetic investigation by the time dependence bulk ATRP of styrene. It is the first long alkyl chain initiator which is investigated for the kinetic data of styrene polymerization.

\section{Materials and Methods}

\subsection{Materials}

Styrene was purchased from Aldrich and it was purified by passing through an alumina column to remove stabilizer and then stirred with $\mathrm{CaH}_{2}$ for $8 \mathrm{~h}$ and filtered. Finally it was stored at $0^{\circ} \mathrm{C}$ under nitrogen prior to use. Copper (I) Chloride was purified by recrystalization in methanol and washed with ether. Bipyridine from Fluka, 2-bromopropionyl bromide and 10-undecen-1-ol were purchased from Aldrich and used without further purification. Triethylamine was distilled over $\mathrm{CaH}_{2}$. All solvents were purified by distillation followed by refluxed with sodium and benzophenone.

\subsection{Analytical Methods}

Molecular weight $\left(M_{n}\right)$ and molecular weight distribution $\left(M_{w} / M_{n}\right)$ of polymer were measured by gel permeation chromatography (Toyo soda HLC-802; Column, GMH6 × 2 + G4000H8) and eluent, THF as solvent and calibrated by polystyrene standards. ${ }^{1} \mathrm{H}$ and ${ }^{13} \mathrm{C}$ NMR spectra of polymers were recorded at room temperature on a JEOL GX 500 spectrometer operated at $125.65 \mathrm{MHz}$ in pulse Fourier Transform mode with chloroform- $d$ as solvent. The peak of chloroform in chloroform- $d$ (7.26 ppm for ${ }^{1} \mathrm{H}$ and $74.47 \mathrm{ppm}$ for ${ }^{13} \mathrm{C}$ ) was used as internal reference.

\subsection{Synthesis of Initiator $U n B P$}

The Initiator UnBP was synthesized according to the literature procedure [25]. A $5 \mathrm{~g}$ (29.5 mmol) sample of 10-undecene-1-ol (1) and $5 \mathrm{~mL}$ (36 mmol) of triethylamine were dissolved in 80 $\mathrm{mL}$ of THF. The solution was cooled in an ice-water bath. To this solution was added drop-wise $3.20 \mathrm{~mL}$ (30 mmol) of 2bromopropionyl bromide (2) in $20 \mathrm{~mL}$ of THF. The mixture was stirred for another $2 \mathrm{~h}$ at room temperature (1 reacted with 2 to yield $\mathrm{UnBP}$ and $\mathrm{HBr}$; $\mathrm{HBr}$ was absorbed by triethylamine).
Triethylamine hydrogen bromide salt was filtered out. THF in the filtrate was removed under vacuum at room temperature. The residual was dissolved in $\mathrm{CHCl}_{3}$ and washed with $50 \mathrm{~mL}$ of water three times. The aqueous parts were combined and shaken with $50 \mathrm{~mL}$ of fresh $\mathrm{CHCl}_{3}$. The total $\mathrm{CHCl}_{3}$ solution was then dried over anhydrous $\mathrm{CaCl}_{2}$ for overnight. After filtering off the drying agent, $\mathrm{CHCl}_{3}$ was distilled out under vacuum. A brown liquid was obtained. A further distillation under high vacuum gave a colorless liquid; yield $7.60 \mathrm{~g}(82 \%)$.

${ }^{1} \mathrm{H}$ NMR $\left(\mathrm{CDCl}_{3}\right): 5.72 \mathrm{ppm}\left(\mathrm{m}, 1 \mathrm{H}, \mathrm{CH}_{2}=\mathrm{CH}-\right) ; 4.85 \mathrm{ppm}$ $\left(\mathrm{dd}, 2 \mathrm{H},=\mathrm{CH}_{2}\right) ; 4.41 \mathrm{ppm}\left(\mathrm{q}, 1 \mathrm{H}, \mathrm{CH}_{3} \mathrm{CH}(\mathrm{Br})-\mathrm{OC}(\mathrm{O})-\right) ; 4.1$ ppm (t, 2H, -O- $\mathrm{CH}_{2} \mathrm{CH}_{2}$ ) ; 2.00 ppm (q, 2H, $\mathrm{CH}_{2}=\mathrm{CH}-\mathrm{CH}_{2}-$ ); $1.80 \mathrm{ppm}\left(\mathrm{d}, 3 \mathrm{H}-\mathrm{CH}(\mathrm{Br})-\mathrm{CH}_{3}\right), 1.55 \mathrm{ppm}(\mathrm{t}, 2 \mathrm{H},-\mathrm{O}-$ $\left.\mathrm{CH}_{2} \mathrm{CH}_{2-}\right) ; 1.2-1.4$ ppm (m, 14H, - $\mathrm{O}-\mathrm{CH}_{2} \mathrm{CH}_{2}-\left(\mathrm{CH}_{2}\right)_{7^{-}}$

${ }^{13} \mathrm{C}$ NMR $\left(\mathrm{CDCl}_{3}\right): \delta=167.46,136.34,111.47,63.30$, $37.48,31.10,25.71$ - 26.73, 23.05, 18.97 .

\subsection{Polymerization Procedure}

Polymerization was carried out in a $50 \mathrm{~mL}$ Schelnk type reactor equipped with magnetic stirrer in nitrogen atmosphere. The reactor was charged with prescribed amount of $\mathrm{CuCl}$ and bipyridene. Three freeze-pump-thaw cycles were performed, and the tubes were sealed under vacuum with rubber septum. A required amount of degassed styrene and initiator were added with syringe. The reactor was placed in an oil bath held by a thermostat at the desired temperature and the reaction mixture was stirred for certain time. At certain interval, the polymerization was stopped by added methanol followed by cooling the reactor into ice water and the polymer was precipitated in methanol by stirring over night. The polymers obtained were filtered, adequately washed with methanol and dried under vacuum at $60^{\circ} \mathrm{C}$ for $6 \mathrm{~h}$.

\section{Results and Discussions}

Styrene polymerization by ATRP at $110^{\circ} \mathrm{C}$ initiated with three different concentration of UnBP with cupper (I) chloride and bipyridine as a catalyst under nitrogen atmosphere has been reported [25]. The polymerization rate with respect to monomer concentration and the number averaged molecular weight $\left(M_{n}\right)$ of the polymer evolved linearly with conversion. The effect of temperature on polymerization of styrene with $\mathrm{UnBP} / \mathrm{CuCl} / \mathrm{BiPy} \quad(1: 1: 2)$ was investigated at various temperatures $\left(75,110\right.$ and $\left.130^{\circ} \mathrm{C}\right)$. The results obtained are listed in Table 1. The yield of polymers was increased with raising the polymerization temperature. The molecular weight of the polymers was increased and the molecular weight distribution became narrower with raising temperature. The narrow polydispersity $\left(M_{w} / M_{n}=1.50\right)$ of the polymers obtained at 110 and $130^{\circ} \mathrm{C}$ suggests that the living polymerization of styrene should proceed with these conditions. To confirm the living nature at $110^{\circ} \mathrm{C}$, the dependence of $M_{n}$ on polymerization time was investigated by sampling method. $1 \mathrm{~mL}$ of reaction mixture was sampled with a syringe at every 30 minutes during polymerization. The molecular weight and molecular weight distribution of the polystyrene obtained by sampling method were measured by GPC. 
Table 1. Effect of Temperature on bulk Polymerization of styrene ${ }^{a}$.

\begin{tabular}{llllll}
\hline Entry & Temp. $\left({ }^{\circ} \mathbf{C}\right)$ & Conv $(\%)$ & $\boldsymbol{M}_{\mathbf{n}}{ }^{\mathbf{b}}$ & $\boldsymbol{M}_{\mathbf{w}}{ }^{\mathbf{c}}$ & $\boldsymbol{M}_{\mathbf{w}} / \boldsymbol{M}_{\mathbf{n}}{ }^{\mathbf{d}}$ \\
\hline 1 & 75 & 1.0 & 8537 & 15499 & 1.81 \\
2 & 110 & 24.0 & 13956 & 20934 & 1.50 \\
3 & 130 & 39.5 & 14820 & 21236 & 1.45 \\
\hline
\end{tabular}

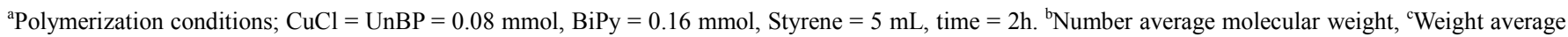
molecular weight and ${ }^{\mathrm{d}}$ Molecular weight distribution were measured by GPC analysis using polystyrene standard.

Table 2. Time dependence polymerization of styrene at $110^{\circ} \mathrm{C}$ by sampling method ${ }^{a}$.

\begin{tabular}{lllllll}
\hline Entry & Time (min.) & Conv. (\%) & $\ln \left(\left[\mathbf{M}_{\mathbf{0}}\right] /[\mathbf{M}]\right)$ & $\boldsymbol{M}_{\mathbf{n}, \mathbf{t h}}{ }^{\mathbf{b}}$ & $\boldsymbol{M}_{\mathbf{n}, \mathbf{e x p}}{ }^{\mathbf{c}}$ & $\boldsymbol{M}_{\mathbf{w}} / \boldsymbol{M}_{\mathbf{n}}{ }^{\mathbf{d}}$ \\
\hline 4 & 30 & 6.5 & 0.07 & 3755 & 4305 & 1.62 \\
5 & 60 & 11.0 & 0.12 & 6151 & 6563 & 1.62 \\
6 & 90 & 18.5 & 0.21 & 10144 & 10168 & 1.56 \\
7 & 120 & 25.0 & 0.29 & 13605 & 13956 & 1.49 \\
8 & 150 & 33.5 & 0.41 & 18132 & 18516 & 1.45 \\
9 & 180 & 39.0 & 0.49 & 21061 & 21147 & 1.45 \\
\hline
\end{tabular}

${ }^{\mathrm{a}}$ Polymerization conditions; $\mathrm{CuCl}=\mathrm{UnBP}=0.08 \mathrm{mmol}$, BiPy $=0.16 \mathrm{mmol}$, Styrene $=5 \mathrm{~mL}$, temperature $=110{ }^{\circ} \mathrm{C},{ }^{\mathrm{b}}$ Theoretical number average molecular weight. ${ }^{\mathrm{c}}$ Number average molecular weight and ${ }^{\mathrm{d}}$ Molecular weight distribution were measured by GPC analysis using polystyrene standard.

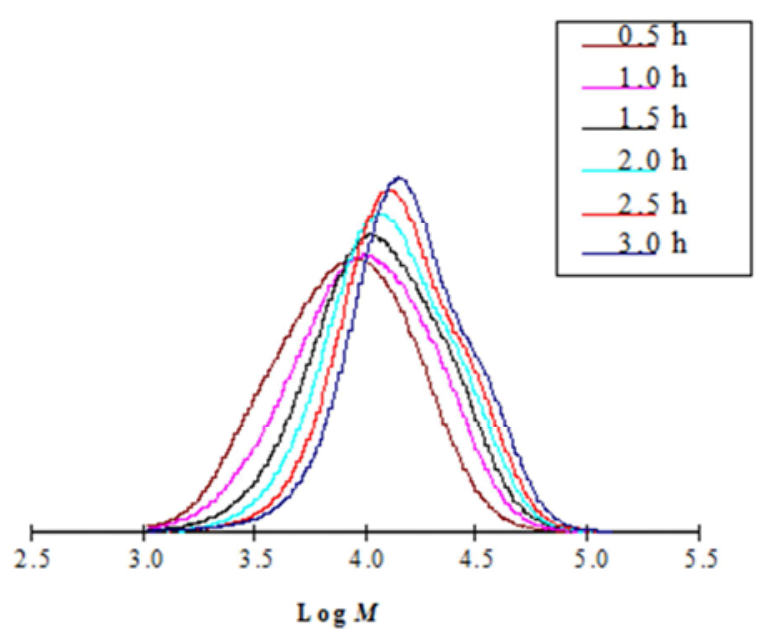

Figure 1. GPC curves of polystyrene obtained form sampling method.

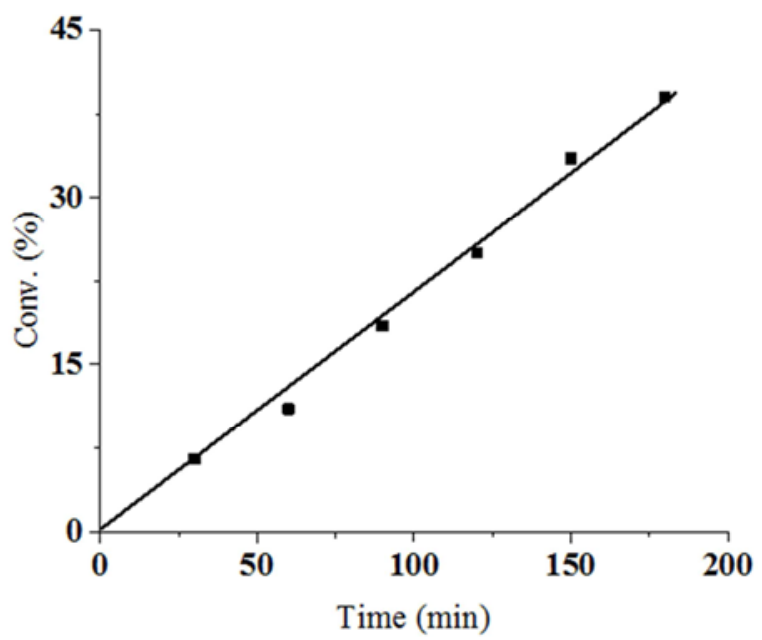

Figure 2. Plot of time vs conversion for the bulk polymerization of styrene at $110^{\circ} \mathrm{C}$ with $\mathrm{UnBP}$ as initiator.

The GPC curves obtained are displayed in Figure 1 and the results are summarized in Table 2. The GPC curves of polymers obtained by sampling method were compared and the curves were shifted to the higher molecular weight region with increasing polymerization time keeping narrow $M_{w} / M_{n}$. The dependence of conversion and of $\ln \left([\mathrm{M}]_{0} /[\mathrm{M}]\right)$ on time for the polymerization of styrene initiated with UnBP, catalyzed by $\mathrm{CuCl} /$ bipy in bulk system is shown in Figure 2 and 3. The linearity of the plot time vs $\ln \left([\mathrm{M}]_{0} /[\mathrm{M}]\right)$ shows that the polymerization follows first order kinetics with respect to the monomer concentration and that the concentration of growing radicals remains constant.

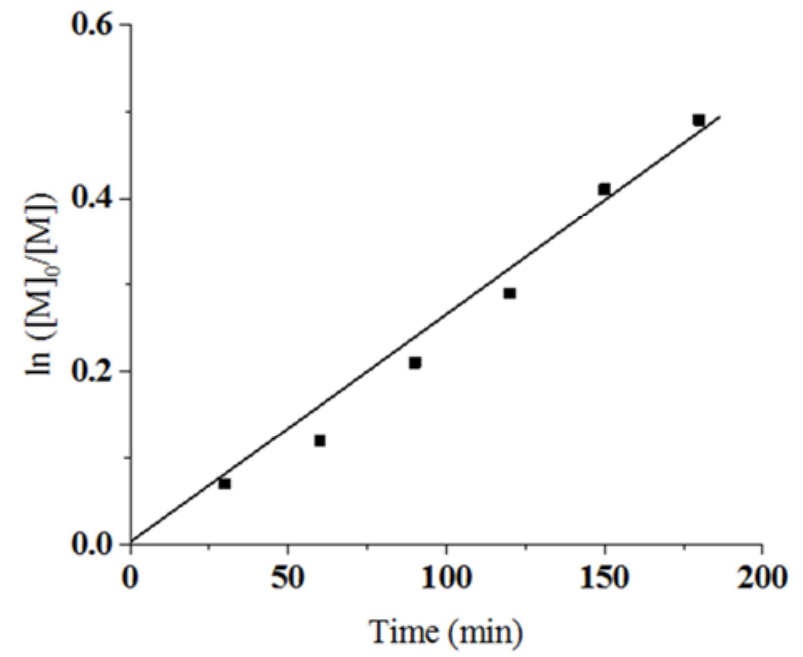

Figure 3. Plot of time vs. $\ln ([M] d[M])$ for the bulk polymerization of styrene at $110^{\circ} \mathrm{C}$ with $\mathrm{UnBP}$ as initiator.

The values of $M_{\mathrm{n}, \mathrm{th}}$ and $M_{\mathrm{n} \text {,exp }}$ for polystyrene sample has been obtained with UnBP as a initiator. All experimental values are slightly higher than the calculated values but increase linearly with conversion (Table 2, Figure 4) demonstrating the living nature of polymerization system. 


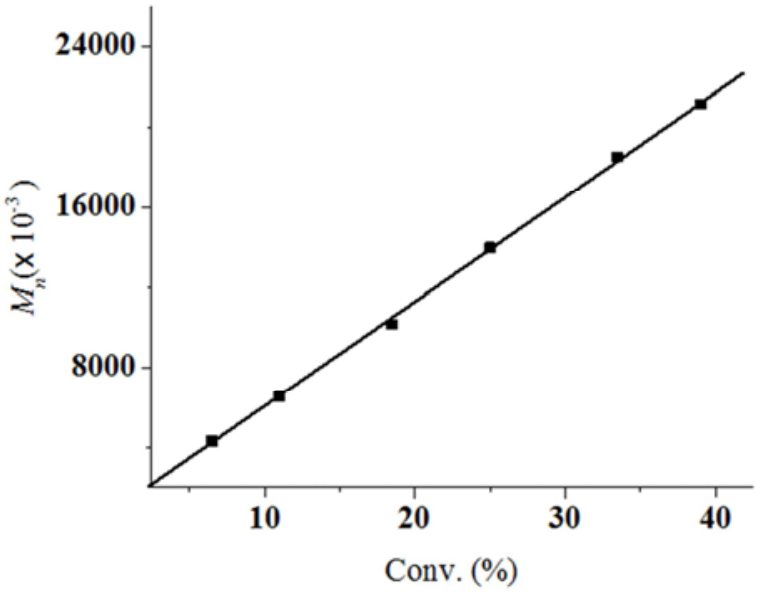

Figure 4. Plot of conversion vs $M_{n}$ for the bulk polymerization of styrene at $110^{\circ} \mathrm{C}$ with UnBP as initiator.

The $M_{n}$ value of the polystyrene linearly increased against conversion. The yield of the sampled polymer also increased linearly with polymerization time. The polydispersity index of all polystyrene samples is typical for polystyrene prepared via ATRP in bulk system.

The structure of polystyrene obtained using UnBP initiator was investigated by ${ }^{1} \mathrm{H}$ and ${ }^{13} \mathrm{C}$ NMR analysis of the polymer. The ${ }^{1} \mathrm{H}$ NMR spectrum of polystyrene the signals at 5.6 and $6.3 \mathrm{ppm}$ assignable to vinyl protons and a signal at $4.7 \mathrm{ppm}$ assignable to $-\mathrm{CH}$ proton of $\alpha-\mathrm{Br}$ indicates that the polymerization was initiated with UnBP. A broad signal at $7.26 \mathrm{ppm}$ assignable to aromatic protons (meta- and paraposition) of styrene unit and at $6.75 \mathrm{ppm}$ for ortho-proton in Figure 5. The signals observed at 1.50 and $2.00 \mathrm{ppm}$ assignable to $-\mathrm{CH}_{2}$ and $-\mathrm{CH}$ protons of main chain of polystyrene.

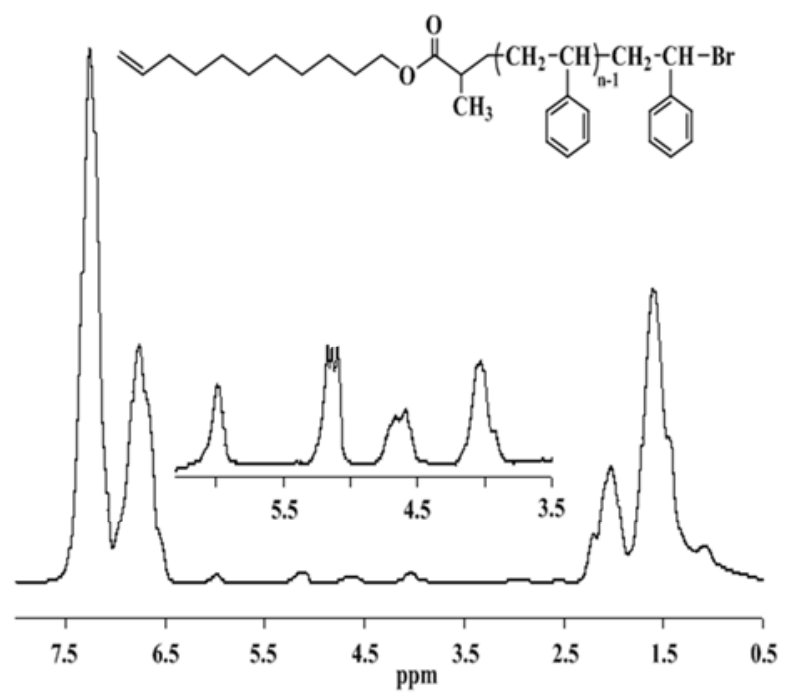

Figure 5. ${ }^{1} H$ NMR spectra of polystyrene obtained by using UnBP as initiator.

The ${ }^{13} \mathrm{C}$ NMR spectrum of polystyrene was showed in the Figure 6. The signals for UnBP unit were clearly observed in the spectrum of the polystyrene. The signals at 136.34 and
$111.47 \mathrm{ppm}$ assignable to vinyl carbons indicate the presence of vinyl chain end in the polystyrene. The signals assignable to styrene unit were also observed in the ${ }^{13} \mathrm{C}$ NMR spectrum of the polymer as follows: $\delta=143,127,126 \mathrm{ppm}$ for aromatic carbons, $50 \mathrm{ppm}$ for $-\mathrm{CH}_{2} \beta$-carbon to $\mathrm{Br}, 43 \mathrm{ppm}$ $\mathrm{CH} \alpha$-carbon to $\mathrm{Br}$ and $38-42 \mathrm{ppm}$ for $-\mathrm{CH}_{2}$ and $-\mathrm{CH}$ carbons of main chain of polystyrene. These results clearly indicate the presence of vinyl group in the $\omega$-end of polystyrene obtained with UnBP initiator.

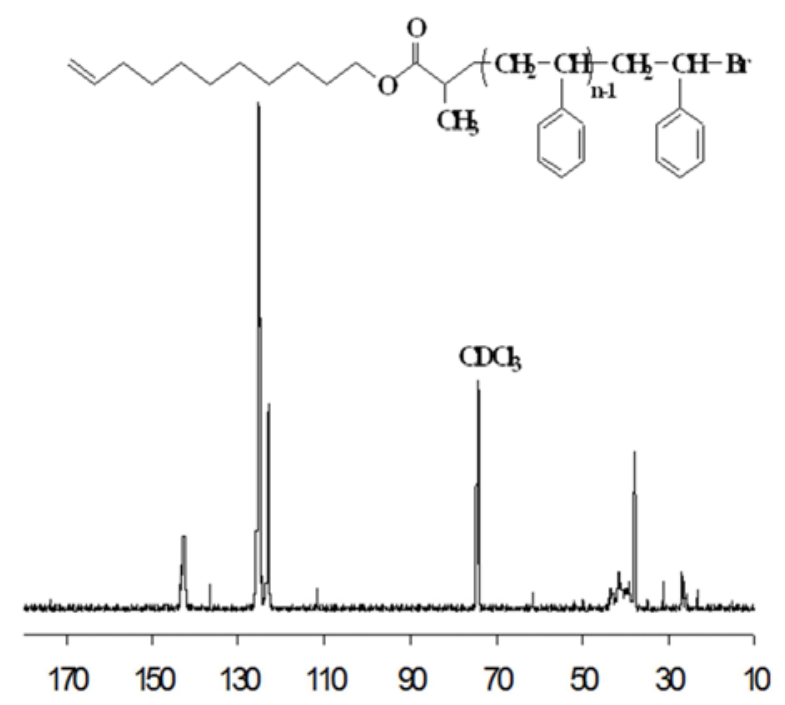

Figure 6. ${ }^{13} \mathrm{C} N M R$ spectra of polystyrene obtained by using UnBP as initiator.

These data can clear that the long chain vinyl end functional polystyrene has been synthesized by ATRP and the polymerization rate was first order with respect to conversion and the number averaged molecular weight $\left(M_{n}\right)$ of the polymer.

\section{Conclusion}

The polymerization of styrene with $\mathrm{Cu}(\mathrm{I}) / \mathrm{Bipy} / \mathrm{UnBP}$ catalyst by ATRP method conducted on different temperatures but it follows the livingness at $110^{\circ} \mathrm{C}$ or more. The kinetic study was successfully confirmed by sampling method at $110^{\circ} \mathrm{C}$. The initiator (UnBP) acts as an efficient initiator for the ATRP of styrene. The yield and the molecular weight of the polymers were increased, and the molecular weight distribution became narrower with raising polymerization temperature and time. Furthermore, for styrene polymerization it is the first initiator with long chains investigated the kinetic data. The feasibility of UnBP as an initiator for the facile preparation of block copolymers via ATRP is currently under investigation.

\section{Acknowledgements}

I am especially grateful to Dr. Jun-ichi Mamiya, Assistant Professor, Chemical Resources Laboratory, Tokyo Institute of technology, Japan for GPC analysis of polymer samples. I am 
also grateful to Dr. Suman Chandra Mohanta, Research Fellow, the Institute of Scientific and Industrial Research (ISIR), Osaka University, Japan for NMR analysis of our samples.

\section{References}

[1] J. S. Wang, K. Matyjaszewski, Controlled/living radical polymerization. Atom transfer radical polymerization in the presence of transition-metal complexes. J. Am. Chem. Soc., 1995a, 117, 5614-5615.

[2] K. Matyjaszewski, J. Xia, Atom transfer radical polymerization. Chem. Rev., 2001, 101 (9): 2921-2990.

[3] Y. Kotani, M. Kato, M. Kamigaito, M. Sawamoto, Living radical polymerization of alkyl methacrylates with ruthenium complex and synthesis of their block copolymers. Macromolecules, 1996, 29, 6979-6982.

[4] K. Matyjaszewski, T. E. Patten, J. Xia, Controlled/Living Radical Polymerization. Kinetics of the Homogeneous Atom Transfer Radical Polymerization of Styrene. J. Am. Chem. Soc., 1997, 119, 674-680.

[5] P. Krys, K. Matyjaszewski, Kinetics of Atom Transfer Radical Polymerization. European Polymer Journal, 2017, 89, 482523.

[6] M. Zhong, Y. Wang, P. Krys, D. Konkolewicz, K. Matyjaszewski, Reversible-Deactivation Radical Polymerization in the Presence of Metallic Copper. Kinetic Simulation. Macromolecules, 2013, 46, 3816-3827.

[7] A. Kajiwara, K. Matyjaszewski, Simultaneous EPR and Kinetic Study of Styrene Atom Transfer Radical Polymerization (ATRP). Macromolecules, 1998, 31, 56955701.

[8] T. E. Patten, J. Xia, T. Abernathy, K. Matyjaszewski, Polymers with Very Low Polydispersities from Atom Transfer Radical Polymerization. Science, 1996, 272, 866-868.

[9] V. Percec, B. Barboiu, A. Neumann, J. C. Ronda, M. Zhao, Metal-Catalyzed Living Radical Polymerization of Styrene Initiated with Arenesulfonyl Chlorides. From Heterogeneous to Homogeneous Catalysis. Macromolecules, 1996, 29, 3665 3668 .

[10] K. Y. Choi, J. S. Chung, B. G. Woo, M. H. Hong, Kinetics of Slurry Phase Polymerization of Styrene to Syndiotactic Polystyrene with Pentamethyl Cyclopentadienyl Titanium Trimethoxide and Methyl Aluminoxane. I. Reaction Rate Analysis. Journal of Applied Polymer Science, 2003, 88, 2132-2137.

[11] H. Roghani-Mamaqani, V. Haddadi-Asl, K. Khezri, M. Salami-Kalajahi, Mohammad Najafi, Kinetic Study of Styrene Atom Transfer Radical Polymerization From Hydroxyl Groups of Graphene Nanoplatelets: Heterogeneities in Chains and Graft Densities. Polymer engineering and science, 2015, 55(8): 1720-1732.

[12] N. Rattanathamwat, J. Wootthikanokkhan, N. Nimitsiriwat, C. Thanachayanont, U. Asawapirom, Kinetic Studies of Atom Transfer Radical Polymerisations of Styrene and
Chloromethylstyrene with Poly(3-hexyl thiophene) Macroinitiator. Advances in Materials Science and Engineering, Volume 2015.

[13] T. G. Ribelli, P. Krys, Y. Cong, K. Matyjaszewski, Model Studies of Alkyl Halide Activation and Comproportionation Relevant to RDRP in the Presence of $\mathrm{Cu}^{0}$. Macromolecules, 2015, 48, 8428-8436.

[14] V. Percec, H.-J. Kim, B. Barboiu, Disulfonyl Chlorides: A Universal Class of Initiators for Metal-Catalyzed Living Diradical Polymerization of Styrene(s), Methacrylates, and Acrylates. Macromolecules, 1997, 30, 6702-6705.

[15] P. Krys, T. G. Ribelli, K. Matyjaszewski, A. Gennaro, Relation between Overall Rate of ATRP and Rates of Activation of Dormant Species. Macromolecules, 2016, 49, 2467-2476.

[16] L. Cavin, A. Rouge, T. Meyer, A. Renken, Kinetic modeling of free radical polymerization of styrene initiated by the bifunctional initiator 2,5-dimethyl-2,5-bis(2-ethyl hexanoylperoxy)hexane. Polymer, 2000, 41, 3925-3935.

[17] A. Neumann, H. Keul, H. Hocker, Atom transfer radical polymerization (ATRP) of styrene and methyl methacrylate with $\alpha, \alpha$-dichlorotoluene asinitiator; a kinetic study. Macromol. Chem. Phys., 2000, 201, 980-984.

[18] C. Peng, M. Zhong, Y. Wang, Y. Kwak, Y. Zhang, W. Zhu, M. Tonge, J. Buback, S. Park, P. Krys, D. Konkolewicz, A. Gennaro, K. Matyjaszewski, Reversible-deactivation radical polymerization in the presence of metallic copper. Activation of alkyl halides by $\mathrm{Cu}^{0}$. Macromolecules, 2013, 46 (10): 3803-3815.

[19] Y. Fu, A. Mirzaei, M. F. Cunningham, R. A. Hutchinson, Atom-Transfer Radical Batch and Semibatch Polymerization of Styrene. Macromol. React. Eng., 2007, 1, 425-439.

[20] Y. Wang, N. Soerensen, M. Zhong, H. Schroeder, M. Buback, K. Matyjaszewski, Improving the "Livingness" of ATRP by Reducing Cu Catalyst Concentration. Macromolecules, 2013, 46, 683-691.

[21] Fischer, H. Unusual selectivities of radical reactions by internal suppression of fast modes. J. Am. Chem. Soc., 1986, 108, 3925-3927.

[22] X. Li, W. Wen-Jun, L. Bo-Geng, S. Zhu, Kinetics and Modeling of Solution ARGET ATRP of Styrene, Butyl Acrylate, and Methyl, Methacrylate. Macromol. React. Eng., 2011, 5, 467-478.

[23] R. Dagmar, D'hooge, D. Konkolewicz, R. Marie-Francois, G. B. Marin, K. Matyjaszewski, Kinetic Modeling of ICAR ATRP $^{\mathrm{a}}$. Macromol. Theory Simul., 2012, 21, 52-69.

[24] A. P. Haehnel, S. Fleischmann, P. Hesse, H. Klaus-Dieter, C. Barner-Kowollik, Investigating $\mathrm{Cu}(0)$-Mediated Polymerizations: New Kinetic Insights Based on a Comparison of Kinetic Modeling with Experimental Data ${ }^{a}$. Macromol. React. Eng., 2013, 7, 8-23.

[25] T. Hasan, A. K. Sarker. New Epoxy End-Functional Polystyrene Synthesized by Atom Transfer Radical Polymerization. Asian Journal of Chemistry, 2009, 21, 5, 3939-3946. 